\title{
Comments on the High Pressure Preservation of Human Milk
}

\author{
S. J. Rzoska ${ }^{1 *}$, E. Rosiak ${ }^{1,2}$, M. Rutkowska ${ }^{1}$, A. Drozd-Rzoska ${ }^{1}$, A. Wesolowska ${ }^{3} \&$ M. K. \\ Borszewska-Kornacka ${ }^{4}$ \\ ${ }^{1}$ Institute of High Pressure Physics Polish Academy of Sciences, Warsaw, Poland \\ ${ }^{2}$ Warsaw University of Life Sciences-SGGW, Warsaw, Poland \\ ${ }^{3}$ Warsaw Medical University, Faculty of Health Science and Laboratory of Milk and Lactation \\ Research at the Regional Bank of Human Milk, Warsaw, Poland \\ ${ }^{4}$ Warsaw Medical University, Clinic of Neonatology and Intensive Care of the Newborn, Warsaw, \\ Poland
}

*S. J. Rzoska, E-mail: sylwester.rzoska@unipress.waw.pl

Received: August 17, 2017

doi:10.22158/fsns.v1n2p71
Accepted: August 26, 2017

URL: http://dx.doi.org/10.22158/fsns.v1n2p71

\section{Abstract}

The current state of studies on the high pressure preservation of the human milk is briefly presented. It is indicated that reaching (i) the antimicrobial safety, (ii) antiviral safety, and (iii) high nutritional, metabolic and immunological quality, may be difficult for a "classical" single pressure pulse High Pressure Preservation (HPP) treatment. It is shown that the sudden decompression leads to additional physical processes, which can be important for supporting the HPP technology. Additional advantages were reached due to the two-pulse compression, with subsequent values: $P=200 \mathrm{MPa}$ and $400 \mathrm{MPa}$. Tests included the microbiological insight for the two-weeks storage. It is also shown that the decay of the number of microorganisms under the high pressure follows the relation $n(t)=n_{0} \exp (A t) \exp \left(B t^{2}\right)$. Finally, issues regarding containers for the high pressure preservation of human milk are discussed.

\section{Keywords}

human milk, foods preservation, high pressures, thermodynamics, microbiology

\section{Introduction}

The human milk is not only the first food for new born infants. It is the natural continuation of the intrauterine nutrition which delivers the energy and enables the development. Human milk is essential for avoiding many chronic diseases during the whole life, being the source of constituents important in metabolic processes. For instance, epidemiological data show the protective role of the human milk to prevent acute and chronic diseases and obesity. If the breastfeeding of newborn is not possible, the best solution seems to be banks of human milk (Mimouni et al., 2017). Nowadays, the microbiological safety in human milk banks is assured via the Holder "soft" pasteurization: the thermal treatment at $T=$ 
$62.5^{\circ} \mathrm{C}$ for $t=30 \mathrm{~min}$ (Kim \& Unger, 2010). However, any protocol associated with approaching or passing the pasteurization threshold, required for reaching the microbiological safety, is associated with the very notable reduction of key nutritional and bioactive features (Peila et al., 2016). The New Hope for banks of human milk can be the implementation of innovative methods based on non-thermal physical treatments (Peila et al., 2017). The most prominent candidate seems to be the High Pressure Preservation (HPP), which has already reached a great success in the pro-health foods market. The key features of the HPP technology can be concluded as follows (Boziaris, 2014; Huang et al., 2016; Barba et al., 2017):

$\checkmark \quad$ Microbiological safety even up to 90 days,

$\checkmark \quad$ Taste, flavor and texture of fresh foods,

$\checkmark \quad$ Vitamins content and nutritional characterizations of fresh foods,

$\checkmark \quad$ Bioactivity close to the fresh product and long-time preserved,

$\checkmark \quad$ The lack of chemical preservatives,

$\checkmark \quad$ Using of salt can be avoided,

$\checkmark \quad$ In selected cases deactivation of enzymes is possible,

$\checkmark \quad$ The tool for the creation of new functional foods,

$\checkmark \quad$ Used for already packed foods: the secondary microbiological contamination can be avoided,

$\checkmark \quad$ Applicable for fluid and "solid" products,

$\checkmark \quad$ Isotropic and "almost immediate" action of pressure on the product,

$\checkmark \quad$ Environment-friendly method: no pollutions and it requires up to 10x less energy than the thermal pasteurization.

One can expect that these extraordinary advantages of the HPP technology have to occur also for the human milk. However, human milk is much more than simply a food. It is an extremely complex system, being also one of the most important factors shaping the human health for the whole life (Mimouni et al., 2017). Consequently, possible implementations of the HPP technology for human milk banks require careful optimization and consideration of all possible issues.

This report discusses problems of the HPP technology application for the human milk. It focuses on physical issues which have been not clearly addressed so far, including compressing protocols and the convenient packing.

\section{Method}

New experimental results presented in this report are based on the application of large volume high pressure processors, working up to $P>600 \mathrm{MPa}$ and in the possible temperature range from $-20^{\circ} \mathrm{C}$ to $120^{\circ} \mathrm{C}$. The working volumes of pressure chambers: $V=1 \mathrm{~L}$ and $V=2 \mathrm{~L}$ They enable "programming" of the form of high pressure pulses (see the description below) and measurement of temperature via thermocouples located within the chamber. Both processors were designed and manufactures in the Institute of High Pressure Physics Polish Academy of Sciences (Warsaw, Poland). Samples of human milk were collected via the Bank of Human Milk at Warsaw Medical University (see below). Prior to 
the high pressure treatments the human milk samples were place in special container able to $20 \%-30 \%$ decrease of volume without any permanent and non-reversible distortions. All details regarding containers and microbiological tests are given is subsequent paragraphs.

\section{Results}

\subsection{Emerging Optimal Parameters of HPP Processing of Human Milk}

Generally, studies of the high pressure based preservation of human milk explore the pattern developed for the food industry: the high compression in the range between 300 and $600 \mathrm{MPa}$, for few/several minutes, at the near room temperature. The key target in this treatment is the high microbiological safety (Huang et al., 2016). This pattern is also applied in studies on the human milk pascalization carried out so far (Vazquez-Landaverde et al., 2006; Viazis, 2008; Viazis et al., 2008; Permanyer et al., 2010; Moltó-Puigmartí et al., 2011; Lou et al., 2012; Delgado et al., 2014; Sousa et al., 2014; Windyga et al., 2015; Sousa et al., 2016; Kiełbratowska \& Kołodziejska, 2017; Li et al., 2017). Tables 1 and 2 below illustrate some recent results, focusing on trends and the scatter of experimental data.

Table 1. Selected Result Showing the Decrease of the Number of Key Parasitic Microorganisms on Compressing

\begin{tabular}{llllll}
\hline Microorganism & $\boldsymbol{n}$ & $\boldsymbol{n}$ & $\boldsymbol{n}$ & $\boldsymbol{T}\left({ }^{\mathbf{0}} \mathbf{C}\right)$ & Ref. \\
& $\mathbf{4 0 0} \mathbf{~ M P a}$ & $\mathbf{5 0 0} \mathbf{M P a}$ & $\mathbf{6 0 0} \mathbf{M P a}$ & & \\
\hline Staphylococcus aureus & $5 \log / 30 \mathrm{~min}$ & & $21-31$ & {$[1]$} \\
Staphylococcus aureus & $6-8 \log / 30 \mathrm{~min}$ & & $21-31$ & {$[1]$} \\
Staphylococcus aureus & $5 \log / 15 \mathrm{~min}$ & & 4 & {$[1]$} \\
Staphylococcus aureus & $8 \log / 15 \mathrm{~min}$ & & 50 & {$[1]$} \\
Staphylococcus aureus & $2.5 \log / 15 \mathrm{~min}$ & $5 \log / 15 \mathrm{~min}$ & 4 & {$[2]$} \\
Staphylococcus aureus & $2 \log / 15 \mathrm{~min}$ & $4 \log / 15 \mathrm{~min}$ & & 20 & {$[2]$} \\
Staphylococcus aureus & $3.5 \log / 50 \mathrm{~min}$ & $8.5 \log / 15 \mathrm{~min}$ & & 50 & {$[2]$} \\
Streptococcus agalactiae & $8 \log / 7 \mathrm{~min}$ & & $21-31$ & {$[1]$} \\
Listeria monocytogenes & $8 \log / 2 \mathrm{~min}$ & & $21-31$ & {$[1]$} \\
Escherichia coli & $8 \log / 10 \mathrm{~min}$ & & $21-31$ & {$[1]$} \\
gram positive bacteria & & $5 \log$ & $5 \log$ & 30 & {$[3]$} \\
gram negative bacteria & $5 \log$ & & & 30 & {$[3]$} \\
yeast, molds & $300-400$ & & 30 & {$[3]$} \\
\hline
\end{tabular}

Note. The decay $(\mathrm{cfu} / \mathrm{mL})$ is presented in "customary $n$-log units" reflecting the change in the number of microorganism following the HPP process: $n=\log _{10}$ (native/treatead). [1]—(Viazis, 2006; Viazis et al., 2008), [2]—(Windyga et al., 2015), [3]—(Mimouni et al., 2017). 
Table 2. Key Metabolic and Immunological Factors of the Human Milk after the HPP Treatment and after the Reference "Classical" Thermal Holder Pasteurization

\begin{tabular}{|c|c|c|c|c|c|}
\hline Factor & 0.1 MPa (Holder) & $400 \mathrm{MPa} /$ duration & $600 \mathrm{MPa} /$ duration & $T\left({ }^{\circ} \mathrm{C}\right)$ & Ref. \\
\hline $\operatorname{IgA}$ & $72 \%$ & $100 \% / 5 \mathrm{~min}$ & $69.3 \%$ & 12 & {$[1]$} \\
\hline SIgA & $51.2 \%$ & $107 \% / 30 \mathrm{~min}$ & & 30 & {$[2]$} \\
\hline lysozome & $51.2 \%$ & $99.6 \% / 6 \mathrm{~min}$ & $72.7 \% / 6 \mathrm{~min}$ & 30 & {$[2]$} \\
\hline$\alpha$-Tocopherol & $74.5 \%$ & $71 \% / 6 \mathrm{~min}$ & $72.6 \% / 6 \mathrm{~min}$ & 10 & {$[3]$} \\
\hline$\gamma$-Tocopherol & $52.7 \%$ & $83.3 \% / 6 \mathrm{~min}$ & $56.4 \% / 6 \mathrm{~min}$ & 10 & {$[3]$} \\
\hline$\delta$-Tocopherol & $66.7 \%$ & $102.9 \%$ & $75 \% / 6 \mathrm{~min}$ & 10 & {$[3]$} \\
\hline saturated fatty acids & $99.3 \%$ & $95.5 \% / 6 \mathrm{~min}$ & $98.8 \%$ & 10 & {$[3]$} \\
\hline polysaturated fatty acids & $99.6 \%$ & $99.2 \% / 6 \mathrm{~min}$ & $83.7 \% / 6 \mathrm{~min}$ & 10 & [3] \\
\hline monounsaturated fatty acids & $99.6 \%$ & $90.8 \% / 6 \mathrm{~min}$ & $106.3 \% / 6 \mathrm{~min}$ & 10 & [3] \\
\hline interleukin (6) & $25.4 \%$ & $35 \% / 6 \mathrm{~min}$ & $102 \% / 6 \mathrm{~min}$ & 10 & {$[3]$} \\
\hline interferon & $55 \%$ & $93.8 \% / 6 \mathrm{~min}$ & $99 \%$ & 10 & {$[3]$} \\
\hline tumour necrosis factor & $5 \%$ & $100 \%$ & $111 \% / 6 \mathrm{~min}$ & 10 & {$[3]$} \\
\hline vitamin $\mathrm{C}$ & $84 \%$ & $100 \%$ & $100 \%$ & 20 & [4-7] \\
\hline ascorbic acid & $80 \%$ & $100 \% / 15 \mathrm{~min}$ & $100 \%$ & 20 & [4-8] \\
\hline lysozome & $56 \%$ & & $100 \% / 15 \mathrm{~min}$ & 20 & {$[5-8]$} \\
\hline
\end{tabular}

Note. Prepared basing on recent results from refs.: [1]—(Permanyer et al., 2010), [2]—(Viazis, 2008), [3]—(Delgado, 2014), [4]—(Moltó-Puigmartí et al., 2011), [5]—(Sousa et al., 2014), [6]—(Sousa et al., 2016), [7]—(Mimouni et al., 2017), [8]—(Montserrat et al, 2016).

Table 3. The Analysis of the Multi-Cycle HP Treatment (Duration $t=6-10 \mathrm{~min}$ )

\begin{tabular}{|c|c|c|c|c|c|}
\hline \multirow[t]{2}{*}{ Factors } & \multirow{2}{*}{$\begin{array}{l}\text { Holder } \\
P=0.1 \mathrm{MPa}\end{array}$} & \multicolumn{2}{|c|}{$n \%$} & \multirow[t]{2}{*}{ Temp. $\left({ }^{\circ} \mathrm{C}\right)$} & \multirow{2}{*}{$\begin{array}{l}\text { number } \\
\text { of cycles }\end{array}$} \\
\hline & & $P=325 \mathrm{MPa}$ & $P=425 \mathrm{MPa}$ & & \\
\hline \multirow[t]{2}{*}{ Nutritional: Energy } & $101 \%$ & $101 \%$ & $99.5 \%$ & 4 & $1-4$ \\
\hline & & $99 \%$ & $99.5 \%$ & 37 & $1-4$ \\
\hline \multirow[t]{2}{*}{ Nutritional: Lipids } & $102 \%$ & $98 \%$ & $98 \%$ & 4 & $1-4$ \\
\hline & & $97 \%$ & $97.6 \%$ & 37 & $1-4$ \\
\hline \multirow[t]{2}{*}{ Nutritional: Protein } & $102.2 \%$ & $95 \%$ & $99.2 \%$ & 4 & $1-4$ \\
\hline & & $92 \%$ & $101 \%$ & 37 & $1-4$ \\
\hline \multirow[t]{2}{*}{ Immunological: $\operatorname{Ig} A$} & $66 \%$ & $92 \%$ & $94 \%$ & 4 & $1-4$ \\
\hline & & $92 \%$ & $82 \%$ & 37 & $1-4$ \\
\hline \multirow[t]{2}{*}{ Immunological: $\operatorname{Ig} G$} & $68 \%$ & $117 \%$ & $90 \%$ & 4 & $1-4$ \\
\hline & & $112.5 \%$ & $87 \%$ & 37 & $1-4$ \\
\hline \multirow[t]{2}{*}{ Immunological: IgM } & $32 \%$ & $111 \%$ & $73.5 \%$ & 4 & $1-4$ \\
\hline & & $104 \%$ & $48 \%$ & 37 & $1-4$ \\
\hline
\end{tabular}




\begin{tabular}{llllll}
\hline Metabolic: lactoferrin & $16 \%$ & $100 \%$ & $63 \%$ & 4 & $1-4$ \\
& & $113 \%$ & $84 \%$ & 37 & $1-4$ \\
Metabolic: lysozome & $71 \%$ & $97 \%$ & $94.6 \%$ & 4 & $1-4$ \\
Metabolic: lipase & $48.5 \%$ & $31 \%$ & $99 \%$ & 37 & $1-4$ \\
& & $101 \%$ & $43 \%$ & 4 & $1-4$ \\
Bacterial load decay & $1.4-3.4$ & & $66 \%$ & 37 & $1-4$ \\
("log units") & & & $1.9-3.1$ & 4 & 4 \\
& & $\sim 4.4$ & & 37 & 4 \\
& & $\sim 5.1$ & & 37 & 1 \\
& & $\sim 5.1$ & & 37 & $1+2$ \\
& & & & 37 & $1+2+3$ \\
& & & & & $1+2+3+4$ \\
\hline
\end{tabular}

Note. Prepared using results of ref.: (Girard et al., 2016).

Recently, HPP studies of human milk focused on the impact of the sequence of high pressure pulses (lasting 6-10 minutes), with respect to nutritional, immunological and metabolic factors have been carried out (Girard et al., 2016). Their results are concluded in Table 3. The emerging picture from above results can be concluded as follows:

$\checkmark \quad$ The post-HPP treatment nutritional, metabolic and immunological features are close to the native human milk, whereas the thermal HPP treatment is notably destructive. It seems that the optimal values of pressure is located for $P=300-400 \mathrm{MPa}$, i.e., in the region where the deactivation of pathogenic bacteria decreases.

$\checkmark \quad$ The high pressure pascalization offers much better microbiological safety regarding key pathogenic bacteria and the total bacterial load. This target can be reached for $P=400-500 \mathrm{MPa}$. Worth stressing is the notable scatter of results obtained in different laboratories.

Regarding pathogenic viruses the evidence is still limited. Notwithstanding, one can expect that at least in some cases the safety is reached for $P$ > $600 \mathrm{MPa}$. This range of pressures is highly destructive for nutritional, metabolic and immunological factors of human milk.

\subsection{The Form of High Pressure Pulses}

For the high pressure "cold pasteurization" of foods, products are placed within the pressure chamber in a container capable for the reversible elastic deformation caused by the isotropic shrinking during compressing. The high pressure is applied for the time $\Delta t_{\text {rise }}$ up to the planned stationary value which is kept constant for the time $\Delta t_{\text {stat. }}$, usually between 3 and 15 minutes. Subsequently, the high pressure is released within $\Delta t_{\text {decay }}$, down to ambient conditions. Pressure is transmitted to the product/sample via the pressurized medium, most often water with a possible addition of glycol or a similar liquid to facilitate the lubrication of elements of the high pressure processor and to avoid freezing during the 
process. In our studies two HPP processors, designed and build in IHPP PAS, with volumes of pressure chambers $V=2 L(2 r=100 \mathrm{~mm})$ and $V=1 L$ (diameter $2 r=65 \mathrm{~mm})$ were used. For the first processor (type I) the piston method for high compression was used (Yordanov \& Angelova, 2010). In this case the durations of compressing $\left(\Delta t_{\text {rise }}\right)$ and decompressing $\left(\Delta t_{\text {decay }}\right)$ is obligatory in the range of 1-2 minutes. The pattern of high pressure pulse is shown in Figure 1. For the second processor (type II) the high compression was created due to the external pumping system, supported by the pressure mutiplicator. For the possible profile see Figure 2.

The associated changes of temperature are also given (red, dashed curve and the right scale). This is related for type I HPP processor with the piston-manostatic principle, volume $V=2 \mathrm{~L}$, diameter $2 r=$ $100 \mathrm{~mm}$. Fast increasing/decreasing of pressure is coupled to notable changes of temperature, as shown in Figures 1 and 2 (dashed curves in red). This is associated with the adiabatic nature of the process, most often recalled within the ideal gas equation frames: $P V / T=n R=C$ (const.), where $P, T$ and $V$ stand for pressure, temperature and volume; $n$ is the number of moles and $R$ denotes the gas constant (Stanley, 1972; Rzoska et al., 2010).

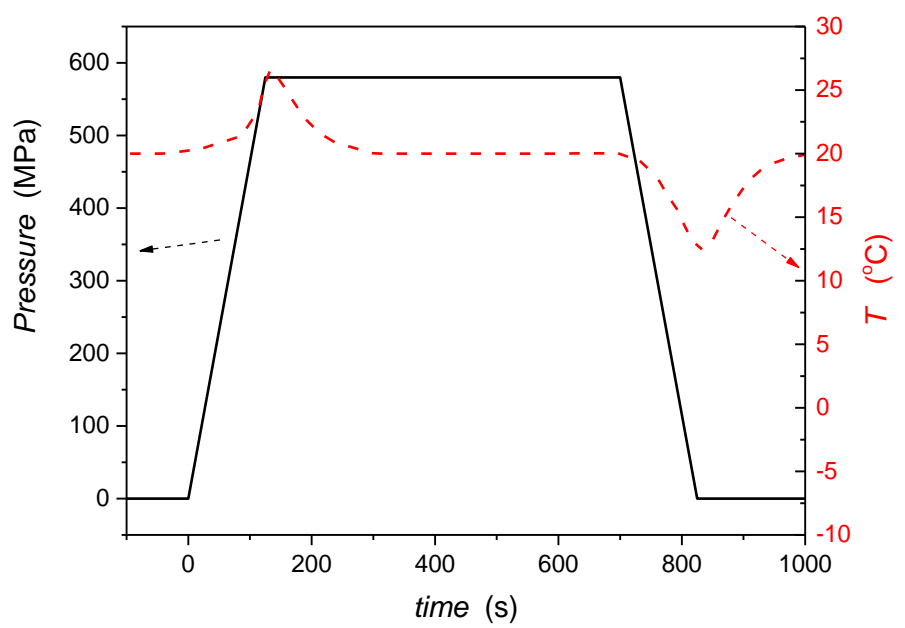

Figure 1. The Form of the Pressure vs. Time Pulse Applied for HP Processing (Solid, Black Lines, Left Scale)

Following this, for adiabatic heating/cooling associated with compressing/decompressing one obtains $T_{\text {finall }} / T_{\text {initial }}=\left(P_{\text {final }} / P_{\text {initial }}-1\right)^{(\gamma-1) / \gamma}$, where $\gamma=c_{p} / c_{V}$ is the ratio of specific heats for constant pressure and volume. Such process is isentropic (the entropy $S=$ const) and it is associated with the notable change of the internal energy $\Delta U=(f / 2) R T_{\text {initial }}\left[\left(P_{\text {final }} / P_{\text {initial }}\right)^{(\gamma-1) / \gamma}-1\right]$. 


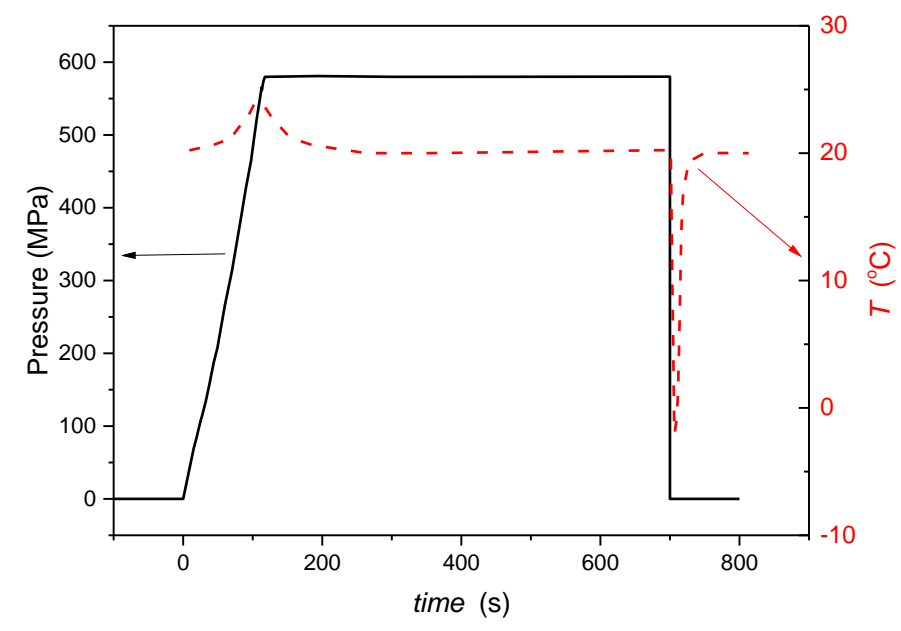

Figure 2. The Form of the Pressure vs. Time Pulse Applied for HPP Processing (Solid, Black Lines, Left Scale)

The associated changes of temperature are also given (red, dashed curve and the right scale). The plot is for the type II HP processor with the external pumping of pressure, volume $V=1 \mathrm{~L}$, diameter $2 r=65$ $\mathrm{mm}$. The temperature sensor was located on the axis of the chamber, $20 \mathrm{~mm}$ below its top.

It is worth stressing that the adiabatic change of pressure and temperature occurs "immediately" and homogeneously within the whole processed sample/material. Ideal adiabatic conditions appears for the perfect thermal isolation from the surrounding or for processes fast enough to reduce the heat exchange from/to surrounding. Above relations although "classical" in discussions on the adiabatic heating/cooling assume the ideal gas equation as the reference. Its validity is limited to gases since for the ideal gas the phase transition to the liquid state is absent (Stanley, 1971). For liquids, a dense and elastic medium, notable repulsive and attractive interactions are significant. Consequently, one can explore solely the isentropic nature of the adiabatic compression/decompression the nature of the given phenomenon, namely:

$$
\begin{gathered}
\Delta S(T, P)=0 \rightarrow d S(T, P)=0 \text { and then } d S(T, P)=\left(\frac{\partial S}{\partial T}\right)_{P} d T+\left(\frac{\partial S}{\partial P}\right)_{P} d P=0 \\
\left(\frac{d T}{d P}\right)_{S}=-\frac{(\partial S / \partial P)_{T}}{(\partial S / \partial T)_{P}}=\frac{V(1 / V)(\partial S / \partial P)_{T}}{T(1 / T)(\partial S / \partial T)_{P}}=T\left(\frac{\alpha_{P}}{\rho c_{P}}\right)
\end{gathered}
$$

where $\alpha_{P}$ is for thermal expansion coefficient, $c_{P}$ denotes the isobaric $\rho$ is for density (Stanley, 1971; Rzoska et al., 2010).

The solution of the latter equation yields ca. $\Delta T \approx 13 \mathrm{~K}$ temperature change for $\Delta P=400 \mathrm{MPa}$ pressure change and $\Delta T \approx 23 K$ for $\Delta P=600 M P a$ pressure jump, assuming water as the host pressurized medium. Notable is the similarity of the above dependence to the $2^{\text {nd }}$ Ehrenfest equation (Stanley, 1971; Rzoska et al., 2010), used for describing the pressure evolution of the phase transition: $d T / d P=(T / \rho)\left(\Delta \alpha_{P} / \Delta c_{P}\right)$, where $\Delta \alpha_{P}$ and $\Delta c_{P}$ are for jumps of the expansion coefficient and the specific heat at the discontinuous phase transition. In the experimental practice for the HP technology 
the rapid change of pressure is mostly adiabatic but some heat exchange also can take place. This can lead to the supplementary change of entropy, related to the Clausius-Clapeyron equation $d P / d T=\Delta S / \Delta V \quad$ (Stanley, 1972; Rzoska et al., 2010).

Figure 1 shows the most classical form of HPP pressure vs. time pulse. First, the pressure increases (for $\left.\Delta t_{\text {rise }}=125 \mathrm{~s}\right)$, subsequently it is kept at the processing pressure for $\Delta t_{\text {stat. }}(\sim 5 \mathrm{~min}$ in Figure 1). Finally, pressure is released for $\Delta t_{\text {decay }}=125 \mathrm{~s}$. This is associated with heating above the base level up to $\Delta T_{\text {rise }} \approx+6.3 \mathrm{~K}$, returning to the base level during the high compression and finally, cooling below the base value by $\Delta T_{\text {decay }} \approx-8.1 \mathrm{~K}$. Both values are below the maximal adiabatic heating/cooling values, what suggests the notable "isothermic contribution" during the rise and decay of pressure. Figure 1 is associated with the type I pressure processor, and the temperature measured on the axis of the pressure chamber, $5 \mathrm{~cm}$. from its top.

Figure 2 presents the pressure vs. time pulse, with the same value of $\Delta t_{\text {rise }}=125 \mathrm{~s}$ and the sudden pressure decay down to the ambient value for $\Delta t_{\text {decay }} \approx 0.1 \mathrm{~s}$. The rise of pressure is associated with $\Delta T_{\text {rise }} \approx+4.1 \mathrm{~K}$ and the decompression related to $\Delta T_{\text {decay }} \approx-21.5 \mathrm{~K}$. This result was obtained in type II pressure processor. It is visible that for the decay one approaches the adiabatic cooling temperature limit. This can be associated with the sudden, very short time decay of pressure. This scenario was realized by opening a valve linked to the pressure chamber.

\subsection{Containers for the HPP Treatment of Human Milk and Fluid Foods}

For the HPP technology, products are placed within an elastic container, made from a plastic (polymer-based) material which does not interact with the product. The container has to ensure the isolation from the pressure-mediated liquid (water, often with lubricated additives as glycol) during the high pressure processing. It also must provide excellent pressure transmission to the product from the pressurized (liquid) medium and the return to the initial state after decompressing (Mertens, 1993; Balasubramaniam et al., 2016). For fluids the container is most often a bottle, consisting from the main body and the closure cap with a sealing system. For the HPP technology the cap should have the same or higher compressibility than the main body. Consequently, the tightness of the closure can increase with rising pressure. A notable problem appears if filling of the bottle is not complete and the "parasitic" air-layer remains. Compressing water up to $P=600 M P a$ results in $\Delta V / V_{0}(\%) \approx 14.6 \%$ relative volume change. For $P=400 M P a$ one obtains $\Delta V / V_{0}(\%) \approx 11.5 \%$. Air is ca. $1.5 \times 10^{8}$ more compressible than water. All these may cause irreversible distortions or even break of the bottle when compressing. This issue is particularly important for HPP implementations in human milk banks, since the human milk is too precious to allow losses associated with the destruction of containers/bottles To solve the problem one can propose the design of the bottle given Figure 3a. It enables an additional anisotropic (longitudinal) shrinkage, what causes that even larger than 20\% "parasitic"; air layer can be easily compensated. 


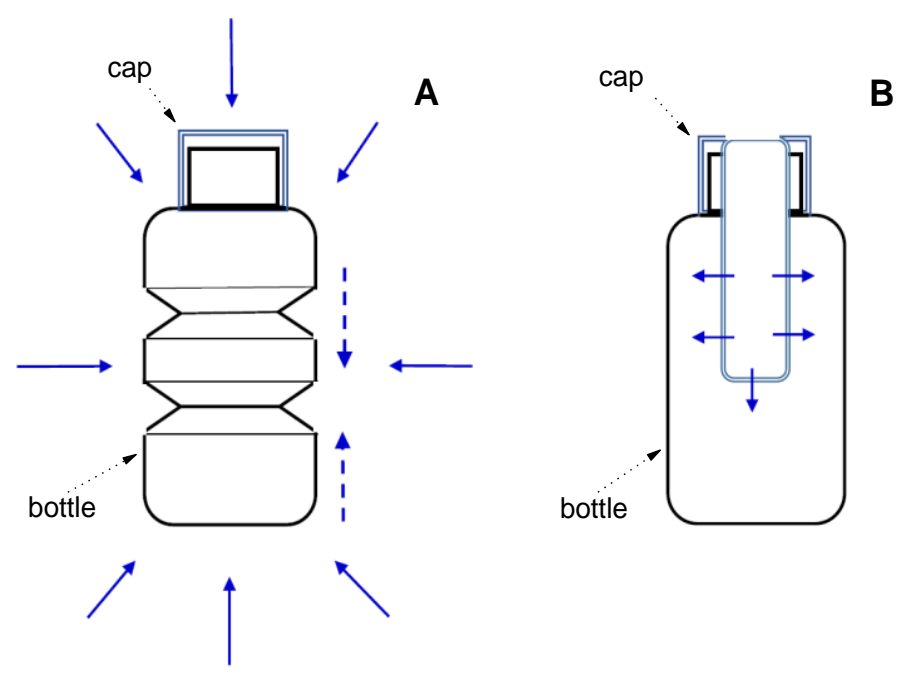

Figure 3. The Proposal of Containers/Bottles for the High Pressure Preservation (HPP) of Human Milk or Other Fluid Foods/Drinks

The solid (thick, blue) arrows indicates the (isotropic) way of compressing. The left bottle (A), made from an elastic plastic, enables HPP processing also in the case if the bottle is only partially filled with the fluid. The dashed (thick, blue) arrows show the additional "anisotropic" shrinkage due to the specific design. All these enable the "safe" compressing of a fluid "product" with a notable air layer inside the bottle. The right part of the figure (B) shows the possibility of making the bottle from an arbitrary material, including the silicate/oxide glass. The pressure is transmitted via increasing the volume of the internal "soft" immersed part (Rzoska \& Drozd-Rzoska, 2017).

Generally, almost non-compressible glass bottles are considered as non-proper for the HPP technology. On the other hand glass-bottles are multi-use, easy-cleaned and free from parasitic interactions with any food, including human milk. Figure 1b shows the possible solution of the "glass bottle problem". The pressure is transmitted to the fluid by means of a properly shaped and "soft" element connected to the cap and immersed in the HPP processed liquid. This element can be also "reversed" and subsequently used as the bottle teat, if made from latex or similar a similar material.

\subsection{Microbiological Tests of the New HPP Protocol}

Figure 4 presents the decay of the number $(N)$ of $S$. aureus bacteria in microbiologically contaminated human milk during such processing at $P=400 \mathrm{MPa}$ for three selected isotherms. Such value of pressure seems to be close to the possible compromise between the antimicrobial safety and the preservation of key constituents (Tables I and II). For the applied semi-log scale the linear dependence is the indicator of the simple exponential decay $N(t)=n_{0} \exp (A t)$, i.e., $\log _{10} N(t)=(1 / \ln 10)\left[n_{0}+A t\right]$ of the number of microorganism for the compressing time $t$. This is the general advised pattern for the microbial deactivation under pressure (Balasubramaniam et al., 2016). A glimpse-test of Figure 4 suggests that such pattern obeys for $T=4^{\circ} \mathrm{C}$ and $T=20^{\circ} \mathrm{C}$ isotherms, but definitively fails for $T=50^{\circ} \mathrm{C}$. Figure 5 presents results of the distortions sensitive and derivative-based analysis of data from Figure 4. 
In the basic case of the simple exponential decay one obtains:

$$
N(t)=n_{0} \exp (A t) \rightarrow d \ln N(t) / d t=A
$$

Such description is related to horizontal lines in Figure 5. However, it obeys only for $T=4^{\circ} \mathrm{C}$ and $T=$ $20^{\circ} \mathrm{C}$ isotherms, for the limited period of time. Results presented in Figure 4 indicate the occurance of the more general pattern:

$$
C(t)=c_{0} \exp (A t) \exp \left(B t^{2}\right) \rightarrow d \ln C(t) / d t=A+2 B t
$$

Horizontal lines in Fig. 5 indicate the clear "single" exponential decay $N(t) \propto \exp (A t)$. Solid curves are for the "extend" exponential decay $N(t) \propto \exp (A t) \exp \left(B t^{2}\right)$ : (i) solid lines are for the process faster than the single exponential decay and described by $B>0$, (ii) the dot-sloped line is for the process slower than the single exponential decay, described by $B<0$ and (iii) for $B=0$ the simple exponential case takes place. Results are obtained basing on experimental data from Figure 4.

In eq. (4) the value $B=0$ is for the simple exponential decay, $B>0$ leads to the decay lesser that the simple exponential one and $B<0$ is for the effective decay stronger the simple \& basic exponential decay. The latter behavior is characteristic for the whole tested time range at $T=50^{\circ} \mathrm{C}$. For $T=4^{\circ} \mathrm{C}$ and $T=20^{\circ} \mathrm{C}$ isotherms the notable change of the behavior during compressing takes place. It is visible that for the' most convenient' for applications isotherm $T=20^{\circ} \mathrm{C}$ the decay of the number of microorganisms is relatively mild, namely only 1.14 "log-unit" for $\mathrm{t}=10 \mathrm{~min}$ compressing and 1.7 "log-unit" for $\mathrm{t}=15 \mathrm{~min}$.

The above resume of recent studies on the HPP technology for human milk focused on (i) microbiological safety, (ii) nutritional, metabolic and immunological agents, and (iii) anti-virus issues. Consequently, the question arises how to overcome the problem of different optimal pressures for these key targets. A possible solution is a new compressing protocol. In ref. (Girard et al., 2016) the application of a sequence of up to 4 pressure pulses $P=400 \mathrm{MPa}$, duration 6-10 minutes each, for instance was tested. Results presented above indicate the necessity of the HPP+ application protocols for human milk, beyond the dominated "classical" HPP pattern, i.e., the single high pressure pulse. In this paragraph results of such HPP+ approach using 2 high pressure pulses are presented: (i) compression at $P=200 \mathrm{MPa}$ for $\Delta t_{\text {stat. }}=10 \mathrm{~min}$, (ii) for $\Delta t_{\text {wait. }}=10 \mathrm{~min}$ samples were kept at $\mathrm{P}=$ $0.1 \mathrm{MPa}$, and finally (iii) the compression at $P=400 \mathrm{MPa}$ for $\Delta t_{\text {stat. }}=10 \mathrm{~min}$ : i.e., the same total period as in the Holder "standard" treatment. Such pattern was successfully tested (Skąpska et al., 2012; Skąpska et al., 2013) in studies on fruits and vegetable juices. 


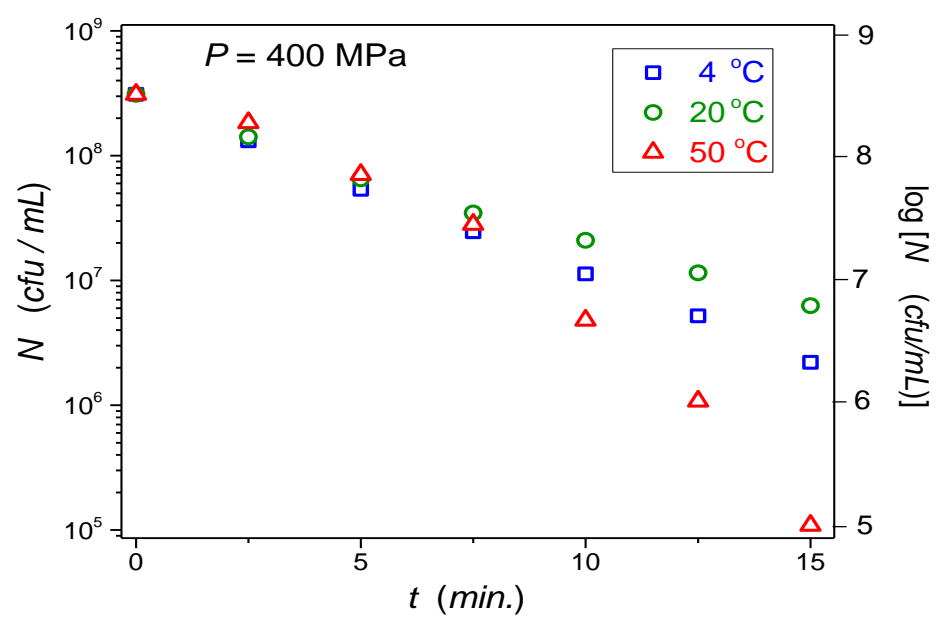

Figure 4. Changes of the Amount of $S$. aureus in Human Milk during $P=400 \mathrm{MPa}$ Compressing, for Selected Temperatures

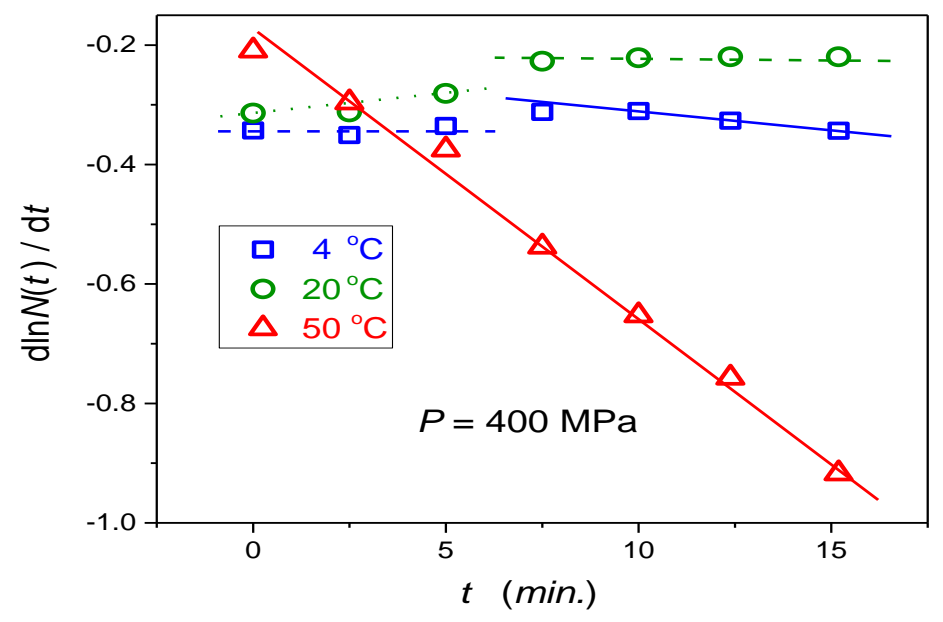

Figure 5. The Derivative of the Amount $(N)$ of $S$. aureus as the Function of Compressing Time

The first moderate-pressure pulse $(P=200 \mathrm{MPa})$ did not influenced the total amount of bacteria but made them more sensitive to impact of the second "killing" high pressure pulse ( $P=400 \mathrm{MPa})$. It is notable that the destruction of spores was also reported. One can speculate that the first pulse weakens the cohesion within cellular walls. Additionally, microbiological consequences of different forms of high pressure pulses shown in Figures 1 (type I) and 2 (type II) were tested. Finally, the storage studies, up to 14 days, were also carried out. For testing the impact of type I (Figure 1) and type II (Figure 2) advanced HPP+ technology human milk was contaminated by S. aureus up to the reference control level $\log 7.47 \mathrm{cfu} / \mathrm{ml}$. The mix of three strains of Staphylococcus aureus: ATCC 25923 commonly used as indicator in high pressure inactivation tests; 4.4. strain isolated from food came from the Department of Industrial Food Microbiology University of Warmia and Mazury in Olsztyn; HM01 strain isolated from raw human milk in the Department of Food Hygiene Warsaw university of Life sciences-SGGW. 
Table 4. Results of Microbiological Test When Applying Different Modes of HPP Treatments

\begin{tabular}{llllll}
\multirow{2}{*}{$\begin{array}{l}\text { Storage } \\
\text { days }\end{array}$} & \multicolumn{5}{l}{ Number of microorganisms during the storage } \\
\cline { 2 - 6 } & Native & $n$ & Relative values & $n$ & Relative values \\
& $n=\log _{10} N$ & $200+400$ (II) MPa & $\Delta n_{D-D} / \Delta n_{0-D}$ & $200+400$ (I) MPa & $\Delta n_{D-D} / \Delta n_{0-D}$ \\
\hline 0 & 7,47 & 4,88 & 2.59 & 3,09 & 4.38 \\
1 & 6,96 & 3,69 & $3.27 / 3.78$ & 3,20 & $3.76 / 4.27$ \\
2 & 7,17 & 4,10 & $3.07 / 3.37$ & 3,75 & $3.42 / 3.72$ \\
4 & 6,71 & 3,81 & $2.09 / 3.66$ & 1,75 & $4.96 / 5.72$ \\
9 & 4,43 & 1,79 & $2.64 / 5.60$ & 0 & $4.43 / 7.47$ \\
14 & 3,91 & 0 & & 0 & \\
\hline
\end{tabular}

Note. $\Delta n_{D-D}=n_{\text {day }}^{\text {native }}-n_{\text {day }}^{\text {pressure }}$ : the index $D$ is for the given day and $D=0$ stands for the reference onset day. For the reference see results of ref. (Windyga et al., 2015) where the single high pressure pulse for $P=400 \mathrm{MPa}, \Delta t_{\text {stat. }}=15 \mathrm{~min}$ at $T=20^{\circ} \mathrm{C}$ yielded ca. 2-log decay of $S$. aureus.

Three replicates of a 14-day storage cycle of humane milk contaminated with Staphylococcus aureus inactivated by high pressure were made. The reference number of $S$. aureus determined in the control sample was changed significantly during the 9 days of refrigerated storage of milk samples. The number of bacteria recorded on that day was $4.43 \mathrm{log} \mathrm{cfu} / \mathrm{ml}$. Changing the number of bacteria by more than two orders of magnitude signified the natural aging of the population of the bacteria tested, as confirmed by the 14th day of storage, in which a $3.91 \mathrm{log} \mathrm{cfu} / \mathrm{ml}$ was found. In $9^{\text {th }}$ day of the storage also in pressure samples (type II), the significant reduction in the tested microorganisms was recorded: down to a level of $1.79 \log \mathrm{cfu} / \mathrm{ml}$. However, the last day of the storage cycle was not labeled S. aureus in the pressurized milk samples. A similar phenomenon took place in the pressure samples in device I. The significant change in the number of bacteria compared to the reference sample was observed on day 4 of storage to level $1.75 \mathrm{log} \mathrm{cfu} / \mathrm{ml}$. Results presented below clearly show the increasing effectiveness of the proposed double-pulse high pressure pattern of compressing, reached already for the near-room temperature of processing $T=20^{\circ} \mathrm{C}$. The obtained result is qualitatively better than for the single pulse for $P=400 \mathrm{MPa}$ processing at the near room temperature. The next notable result is much better reduction of HPP processing for the treatment with the "sudden" decay of pressure (the form of pulse presented in Figure 2). The application of the single 10 minutes, $P=600 \mathrm{MPa}$ completely removes pathogens but it is strongly destructive basic functional features of the human milk. Taking into account results from Table 4 and ref. (Windyga et al., 2015) one can conclude the notable advantage of the 2-pulse scenario, with the properly selected values of compressing, supplemented by the sudden decay of the high pressure pulse. 


\section{Discussion}

This report discusses selected issues associated with the high pressure "cold pasteurization" of human milk. The analysis of experimental data clearly shows that this non-thermal method may lead to results qualitatively better than obtained for the Holder thermal pasteurization, regarding the antimicrobial and antiviral safety as well as the preservation of bioactive nutritional, metabolic and immunological features. However, such completed preservation target seems to be not possible for the single pulse HPP technology.

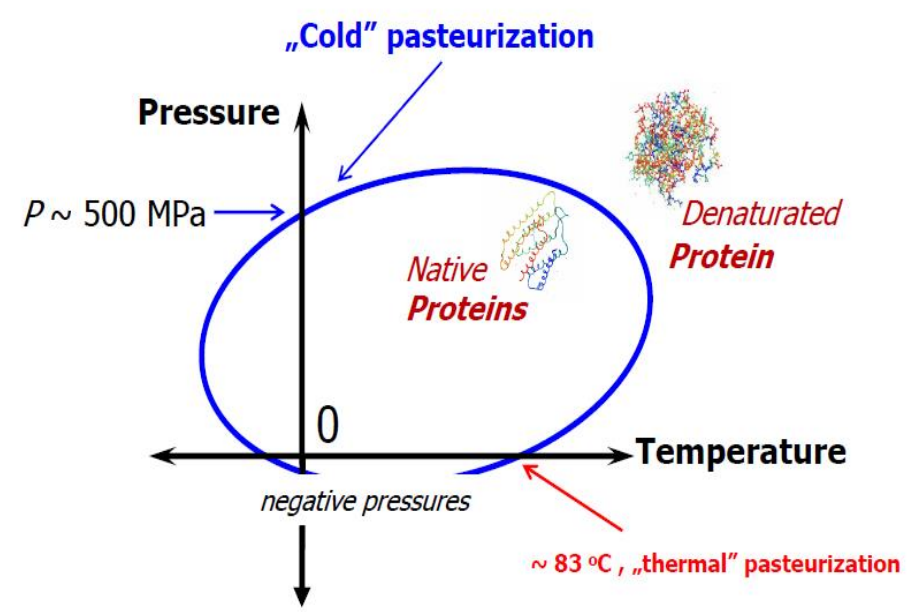

Figure 6. The Sketch of the Denaturation Curve in the Pressure-Temperature Plane: Prepared Following Ref. (Smeller, 2002).

Such breakthrough target seems to be possible only for the expanded "HPP+" approach, such as discussed in this report 2-pulses protocol $(P=200 \mathrm{MPa}$ and $P=400 \mathrm{MPa})$. For presented studies, it has been obtained that results of the treatment can remain valid for the 2-weeks storage. It is worth stressing that the deeper decrease of the number or $S$. aureus occurred for the sudden decompression of high pressure pulses. One can speculate that this is associated with the short-time, deep adiabatic cooling, the pressure-shock change and the pressure-gradient wave front propagated through the tested sample. The analysis of changes of the number of $S$. aureus under $P=400 \mathrm{MPa}$ compression showed that the most often used near room temperature $\left(T=20^{\circ} \mathrm{C}\right)$ for the high pressure processing is less effective than the treatment related to $T=4^{\circ} \mathrm{C}$ and $T=50^{\circ} \mathrm{C}$. The decay of the number of microorganisms was particularly strong for the latter. It is also notable that the obtained decay of the number of microorganism is complex: $N(t) \propto n_{0} \exp (A t) \exp \left(B t^{2}\right)$, i.e., $n=\log _{10} N(t)=C+A t+B t^{2}$, where the constant $C=\log _{10} n_{0} / \ln 10$. The distortions-sensitive analysis $d n(t) / d t=A+2 B t$ revealed that the pattern and then the key mechanism of the decay of microorganisms can change after few minutes of compressing. It is worth recalling that for the thermal pasteurization the process is related mainly to the denaturation of proteins. One can link this to reaching the activation energy high enough to create new intermolecular links between secondary and ternary structures of proteins, definitively 
changing their forms. The resulted denaturation curve extends in the pressure-temperature plane as shown in Figure 6. However, under high pressure appears additional: the break of cellular walls, the destruction of cellular organelle or changes in the permeability of cellular walls (Rzoska et al., 2015; Starzonek et al. 2015). Moreover, the contribution of all these mechanism seems to depend on the distance from the denaturation curve in the $P$ - $T$ plane.

Concluding, it seems that the "revolutionary" expectations for totally safe human milk and with "native" nutritional, metabolic and immunological features, also during, the long term storage in a "home refrigerator" $\left(\sim 8^{\circ} \mathrm{C}\right)$, are justified. However, this requires rather HPP+ treatment, than a simple implementation of the HPP technology used in the food industry.

\section{Acknowledgements}

The authors would like to acknowledge the support of the grant "Lactotechnology as a response to the special nutritional needs of prematurely born children" (Natl. Centre for Res. \& Develop. NCBiR, Poland: for years 2015-2017). ADR was supported by the National Science Centre (NCN, Poland) project, ref. 2016/21/B/ST3/02203.

\section{References}

Balasubramaniam, V. M., Barbosa-Cánovas, G. V., \& Lelieveld, H. L. M. (2016). High Pressure Processing of Food. Springer, Berlin.

Barba, F. J., Sant'Ana A., Orlien, V., \& Koubaa, M. (2017). Innovative technologies for food preservation: Inactivation of spoilage and pathogenic microorganism. AP, New York.

Boziaris, S. (2014). Novel food preservation and microbial assessment techniques. CRC Press, Boca Raton.

Delgado, F. J., Cava, R., Delgado, J., \& Ramírez, R. (2014). Tocopherols, fatty acids and cytokines content of holder pasteurised and high-pressure processed human milk. Dairy Sci. \& Technol., 94, 145-156. https://doi.org/10.1007/s13594-013-0149-y

Girard, M., Dussault, N., Landry, P., Grandmont, M. J., Couture, M. E., Cloutier M., ... Thibault, L. (2016). Impact of Holder pasteurization and high pressure processing on human milk components. Retrieved from http://www.cdbq.net/wp-content/uploads/2016/07/Poster-HMBANA-final.pdf

Huang, H.-W., Wu, S., Lu, J. K., \& Wang, C.-Y. (2016). Current status and future trends of high-pressure processing in food industry. Food Control, 72, 1-8. https://doi.org/10.1016/j.foodcont.2016.07.019

Kiełbratowska, A., \& Kołodziejska, I. (2017). Effect of High Pressure and Sub-Zero Temperature on Total Antioxidant Capacity and the Content of Vitamin C, Fatty Acids and Secondary Products of Lipid Oxidation in Human Milk. Polish Journal Food Nutricional Science, 67, 117-122.

Kim, J. H., \& Unger, S. (2010). Human milk banking. Paediatric Child Health, 15, 595-598.

Li, X., Huang, R., \& Chen. (2017). Evaluation of assays to quantify infectious human norovirus for Published by SCHOLINK INC. 
heat and high pressure inactivation studies using Tulane virus. Food and Environmental Virology, 1-12. https://doi.org/10.1007/s12560-017-9288-2

Lou, F., Huang, P., Neetoo, H., Gurtler, J. B., Niemira, B. A., Chen, H., Jiang, C. X., \& Li, J. (2012). High-pressure inactivation of human norovirus virus-like particles provides evidence that the capsid of human norovirus is highly pressure resistant. Appl. Environ. Microbiol., 78, 5320-5327. https://doi.org/10.1128/AEM.00532-12

Mertens, B. (1993). Packing aspects of high pressure food processing technology. In Packing Technology and Science (Vol. 6, pp. 31-36). J. Wiley \& Sons, NY.

Mimouni, F. B., Koletzko, B., \& Jain, L. (2017). Human milk for preterm infants: Clinics in Perinatology Series. Elsevier, Philadelphia.

Moltó-Puigmartí, C., Permanye, M., Castellote. A. I., \& López-Sabater, M. C. (2011). Effects of pasteurisation and high-pressure processing on vitamin $\mathrm{C}$, tocopherols and fatty acids in mature human milk. Food Chemistry, 124, 697-702. https://doi.org/10.1016/j.foodchem.2010.05.079

Montserrat, M., Ramos, S. J., Martínez-Lorenzo, M. J., Calvo, M., Sánchez, L., \& Pérez, M. D. (2016). Effect of high pressure and heat treatments on IgA immunoreactivity and lysozyme activity in human milk. European Food Research and Technology, 242, 819-898.

Peila, C., Emmerik, N. E., Giribaldi, M., Stahl, B., Ruitenberg, J. E., van Elburg, R. M., ... Cavallarin, L. (2017). Human Milk Processing: A Systematic Review of Innovative Techniques to Ensure the Safety and Quality of Donor Milk. Journal of Pediatric Gastroenterology and Nutrition, 64, 353-361. https://doi.org/10.1097/MPG.0000000000001435

Peila, C., Moro, G. E., Bertino, E., Cavallarin L., Giribaldi, M., Giuliani, F., ... Coscia, A. (2016). The effect of holder pasteurization on nutrients and biologically-active components in donor human milk: A review. Nutrients, 8, 1-19. https://doi.org/10.3390/nu8080477

Permanyer, M., Castellote, C., Ramírez-Santana, C., Audí, C., Pérez-Cano, F. J., Castell M., ... Franch A. (2010). Maintenance of breast milk Immunoglobulin A after high-pressure processing. $J$. Dairy Science, 93, 877-883. https://doi.org/10.3390/nu8080477

Rzoska, S. J., \& Drozd-Rzoska, A. (2017). Submission to the Urzad Patentowy Rzeczpospolitej Polskiej (the Patent Service of the Republic of Poland).

Rzoska, S. J., Mazur, V., \& Drozd-Rzoska, A. (2010). Metastable Systems under Pressure. Springer Verlag, Berlin.

Rzoska, S. J., Musiał, F., Rutkowska, M., Fonberg-Broczek, M., Sokołowska, B., Drozd-Rzoska, A., \& Nowakowska, J. (2015). Simultaneous impact of high pressures and pulsed electric field on Saccharomyces Cerevisiae model system. J. Food Process. Technol., 6, 5.

Skąpska, S., Sokołowska, B., Fonberg-Broczek, M., Niezgoda, A., Chotkiewicz, A., Dekowska, A., \& Rzoska, S. J. (2013). Factors influencing the inactivation of Alicyclobacillus acidoterrestris spores exposed to high hydrostatic pressure in apple juice. High Pressure Research, 33, 73-82. https://doi.org/10.1080/08957959.2013.772170 
Skąpska, S., Sokołowska, B., Fonberg-Broczek, M., Niezoda, K., Dekowska, A., \& Rzoska, S. J. (2012). The combined effect of high pressure and nisin or lysozyme on the inactivation of Alicyclobacillus acidoterrestris spores in apple juice. High Pressure Research, 32, 119-124. https://doi.org/10.1080/08957959.2012.664642

Smeller, L. (2002). Pressure-temperature phase diagrams of biomolecules. Biochimica et Biofisica Acta, 1595, 11-29. https://doi.org/10.1016/S0167-4838(01)00332-6

Sousa, S. G., Delgadillo, I., \& Saraiva, J. A. (2014). Effect of thermal pasteurization and high pressure processing on immunoglobin content and lysosome and lactoperoxidase activity in human colostrum. Food Chemistry, 151, 79-85. https://doi.org/10.1016/j.foodchem.2013.11.024

Sousa, S. G., Delgadillo, I., \& Saraiva, J. A. (2016). Human Milk Composition and Preservation: Evaluation of High-Pressure Processing as a Non-Thermal Pasteurisation Technology. Crit. Rev. Food Sci. \& Nutr., 56, 1043-1060. https://doi.org/10.1080/10408398.2012.753402

Stanley, H. E. (1971, 1992). Introduction to phase transitions and critical phenomena. Pergamon, New York.

Starzonek, S., Rutkowska, M., Rzoska, S. J., Drozd-Rzoska, A., Fonberg-Broczek, M., Sokołowska, B., \& Martinez-Garcia, J. C. (2014). Dielectric spectroscopy of pressurized Saccharomyces cerevisiae. Food Biophysics, 362, 1-6.

Vazquez-Landaverde, P. A., Torres, J. A., \& Qian, M. C. (2006). Effect of high-pressure-moderate-temperature processing on the volatile profile of milk. J. Agric. Food Chem., 54, 9184-9192. https://doi.org/10.1021/jf061497k

Viazis, S. (2006). High pressure processing of human milk for improved nutrient retention and microbial safety (PhD thesis). North Caroline State University.

Viazis, S., Farkas, B. E., \& Jaykus, L. A. (2008). Inactivation of bacterial pathogens in human milk by high-pressure processing. $\quad$ J. $\quad$ Food. Prot., $\quad 71, \quad$ 109-118. https://doi.org/10.4315/0362-028X-71.1.109

Windyga, B., Rutkowska, M., Sokołowska, B., Skąpska, S., Wesołowska, A., Wilińska, M., ... Rzoska, S. J. (2015). Inactivation of Staphylococcus aureus and native microflora in human milk by high pressure processing. High Pressure Research, 36, 1-8.

Yordanov, D. G., \& Angelova, G. V. (2010). High pressure processing for foods preserving. Biotechnol. \& Biotechnol., 24, 1940-1945. https://doi.org/10.2478/V10133-010-0057-8 